AGH DRILLING, OIL, GAS • Vol. 34 • No. 1 • 2017

http://dx.doi.org/10.7494/drill.2017.34.1.15

\author{
Oleg Yu. Vytyaz*
}

\title{
PREDICTION OF CONDITIONS OF LONGTERM OPERATED DRILL PIPES FAILURE
}

\section{INTRODUCTION}

In Ukraine, oil production is $10-12 \%$, and natural gas production is $46-48 \%$ of national needs. However, at a depth of 6.5-7 thousand meters in the Carpathian oil and gas province and the Dnieper-Donets depression huge reserves of oil and gas have been discovered. But drilling at such depths leads to a significant increase in the number of accidents associated with the failure of the drilling string elements. In practice, the cases of the drilling string failure are registered during vertical drilling [1, 2]. In most cases, uncontrolled transverse fracture of the pipe body is caused by the action of considerable fatigue and static loads, high operating pressure and the development of the critical dimensions of external or internal transverse cracks emerging in the points of stress concentrators because of damage or corrosion pits. Thus, in the drilling interval $2500-4500 \mathrm{~m}$ the failure rate increases in 4.8-5 times, and in the interval 4500-5000 m - in 9.8 times. A substantial portion of pipe body failure (38\%) occurs in welded joints, pipe threads or along the pipe body in cross-sections by disruption [2]. It is obviously, that nature of such destruction is determined by the dominant influence of the relevant power factors such as the size, direction and nature of operating loads, resulting in during tripping.

\section{FORMULATION OF THE PROBLEM}

The analysis of sudden failures associated with the drilling string, gives ground to single out a series of factors, combining influences from which in most cases creates conditions for emergency situations. Firstly, they are the conditions of loading, secondly - technical and operational stress concentrators.

* Institute of Petroleum Engineering, Ivano-Frankivsk National Technical University of Oil and Gas, Ivano-Frankivsk, Ukraine 
Provision of safe and reliable operation of the drilling string requires special attention when evaluating and considering the above-mentioned factors and taking appropriate engineering solutions.

As in the process of tripping operations caused by the influence of static load (weight of the drilling string), the most common is the drilling string failure in cross section by its rupture, it is important to determine the parameters of destruction. The objective of this study is the assessment of conditions of continually operated drill pipes failure with existing internal or external transverse annular cracks during tripping in the drilling interval 1000-6000 m, based on the approaches of fracture mechanics.

The main results of the study. The subject of this research is the fragments of two drill pipes with a nominal diameter of $127 \mathrm{~mm}$, which over 17 years have been used for drilling oil and gas fields in western Ukraine. The chemical composition of the studied steels is shown in Table 1.

Table 1

Chemical composition of investigated steel drill pipes

\begin{tabular}{|c|c|c|c|c|c|c|c|c|c|}
\hline \multicolumn{10}{|c|}{ Mass fraction of elements, \% } \\
\hline \multicolumn{10}{|c|}{ S6 2C } \\
\hline $\mathrm{C}$ & $\mathrm{Mn}$ & $\mathrm{Si}$ & $\mathrm{V}$ & $\mathrm{Cu}$ & $\mathrm{Al}$ & $\mathrm{Ni}$ & $\mathrm{S}_{\max }$ & $\mathrm{P}_{\max }$ \\
\hline 0.38 & 1.52 & 0.92 & 0.09 & 0.13 & 0.04 & 0.09 & 0.018 & 0.016 \\
\hline \multicolumn{8}{|c|}{ Mass fraction of elements, \% } \\
\hline $\mathrm{C}$ & $\mathrm{Mn}$ & $\mathrm{Si}$ & $\mathrm{V}$ & $\mathrm{Cu}$ & $\mathrm{Al}$ & $\mathrm{Ni}$ & $\mathrm{S}_{\max }$ & $\mathrm{P}_{\max }$ \\
\hline 0.47 & 0.82 & 0.26 & 0.10 & 0.09 & 0.15 & 0.07 & 0.016 & 0.018 \\
\hline
\end{tabular}

Mechanical characteristics of longterm operated drill pipes steel (see Tab. 2) were determined according to the standard procedure [3] of testing cylindrical specimens on tension.

Table 2

Mechanical properties of drill pipes steel

\begin{tabular}{|c|c|c|c|c|c|c|}
\hline Steel & $\begin{array}{c}\text { Group } \\
\text { of strength }\end{array}$ & $\begin{array}{c}\text { Duration } \\
\text { of operation, } \\
\text { year }\end{array}$ & $\begin{array}{c}\sigma_{B}, \\
\mathrm{MPa}\end{array}$ & $\begin{array}{c}\sigma_{0,2}, \\
\mathrm{MPa}\end{array}$ & $\begin{array}{c}\delta, \\
\%\end{array}$ & $\begin{array}{c}\psi, \\
\%\end{array}$ \\
\hline $36 \Gamma 2 \mathrm{C}$ & "L" & 23 & 790.0 & 605.0 & 12,5 & 27.0 \\
\hline 45 & "K" & 17 & 685.0 & 462.5 & 12.0 & 34.5 \\
\hline
\end{tabular}


The destruction of metal drilling strings were evaluated for energy [4] criterion: crack begins to grow, if the intensity of the released energy $J$ reaches the critical value $J_{c}$ :

$$
J_{*}=J_{C}
$$

The magnitude $J_{I c}$ was experimentally determined by the method [5, 6]. From the experimentally obtained diagram of samples destruction "force-deflection" (Fig. 1) determined was the work A spent on the deformation of the sample with the formed crack $l_{a v}$ (Fig. 2a) as the element of the structure in which it loses its load-bearing properties. For this purpose, five samples cut from pieces of drill pipes of the strength group "L" $200.0 \times 10.0 \times 8.0 \mathrm{~mm}$ size and of strength group " $\mathrm{K}$ " $200.0 \times 10.0 \times 8.40 \mathrm{~mm}$ size. Thus, the critical value $J_{I c}$ was defined as work A referred to the net area of the deformed sample surface $S_{f}$ (Fig. 2b):

$$
J_{I c}=\frac{A}{S_{f}}
$$

a)

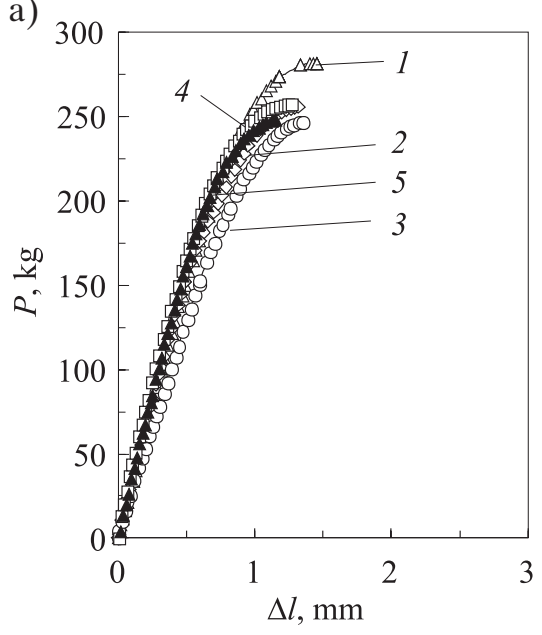

b)

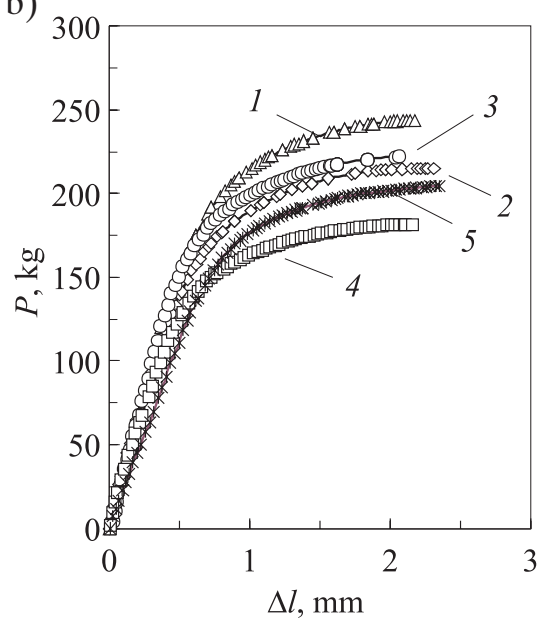

Fig. 1. The stress-strain curve $P-\Delta l$ of samples from drill pipe fragments: a) strength group "L" $(D=126.0 \mathrm{~mm}, d=110.0 \mathrm{~mm}) ; \mathrm{b})$ strength group "K" $(D=126.0 \mathrm{~mm}, d=109.2 \mathrm{~mm})$

a)

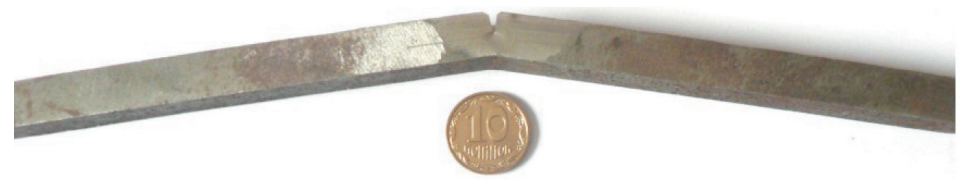

b)

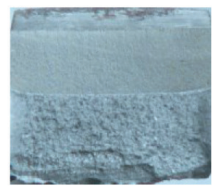

Fig. 2. General view of the sample (a) and the area of its deformed surface (b) after the experiment of researching the conditions of continually operated drill pipes failure 
The value of the stress intensity factor $K_{J c}$ was calculated using the ratio:

$$
K_{J c}=\sqrt{\frac{J_{c} \cdot E}{\left(1-\mu^{2}\right)}}
$$

where:

$J_{c}-$ critical crack resistance;

$E$ - Young's modulus $\left(E=10^{11} \mathrm{~Pa}\right)$;

$\mu$ - Poisson's ratio (for low-alloy steels $\mu=0.3$ ).

Specifications of critical crack resistance (Tab. 3) in the work were given as the critical stress intensity factor $K_{J C}$ and it was calculated by using Equation (3).

Table 3

The value of critical stress intensity factors $K_{J c}$

\begin{tabular}{|c|c|c|c|c|c|c|c|}
\hline Steel & $\begin{array}{c}\text { Group } \\
\text { of strength }\end{array}$ & \multicolumn{4}{|c|}{$\begin{array}{c}K_{J c}, \\
\text { MPa } \sqrt{\mathrm{m}}\end{array}$} & $\begin{array}{c}K_{J c}^{c e p}, \\
\mathrm{MPa} \sqrt{\mathrm{m}}\end{array}$ \\
\hline 36Г2C & "L" & 105.8 & 98.8 & 99.9 & 96.9 & 93.6 & 99.0 \\
\hline 45 & "K" & 130.8 & 129.2 & 130.1 & 130.0 & 133.7 & 130.8 \\
\hline
\end{tabular}

It is also important to estimate the strength and the risk of structural element failure based on the index of "structural element resistance to the crack growth." The depth of the crack $(a / t)^{*}$ at which the rate $\left(d K_{I} / d a\right)$ of stress intensity factors $K_{I}$ change sharply increases $[7,8]$, the system "metal of design - environment" is a characteristic parameter in the achievement of which the likelihood of its destruction significantly increases. In this case, dimensionless dependence of the type:

$$
\frac{\sqrt{t}}{\sigma} \frac{d K_{I}}{d a}=F\left(\frac{a}{t}\right)
$$

is built, where:

$\sigma-$ applied external load;

$t$ - the thickness of structural element in the place of destruction.

Characteristic crack depth $(a / t)^{*}$ is determined by the method [7].

The assessment of conditions of operated drilling string elements with the outer or inner annular crack being under axial load is held with the application of the appropriate analytical dependences [8] to determine the parameters of the stress intensity factors $K_{I}$ 
and their rate of change $d K_{I} / d a$. The resulting calculated data are compared with the results of the calculated and experimental tests of drill pipes operated metal fracture assess. Thus, the main parameters that enable determining the conditions for the drilling string elements destruction are:

- the depth of available internal or external transverse crack $a_{c}$ in the drill pipe;

- the weight of the drilling string $Q^{*}$.

Let's consider the cases of two longterm operated drill pipes failure of the groups of strength "L" $(D=126.0 \mathrm{~mm}, t=8.0 \mathrm{~mm})$ and "K" $(D=126.0 \mathrm{~mm}, t=8.4 \mathrm{~mm})$, which contain external or internal cross annular crack that is under the action of axial load.

To determine the conditions under which the possible destruction of operated drill pipe of strength groups " $\mathrm{L}$ " and " $\mathrm{K}$ ", containing the external circumferential transverse crack with a depth of $(a / t)$ we should consider the calculated scheme depicted in Figure $3 a$.

a)

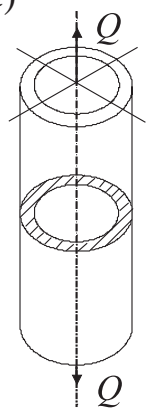

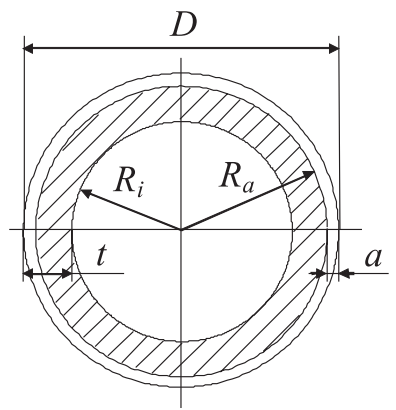

b)

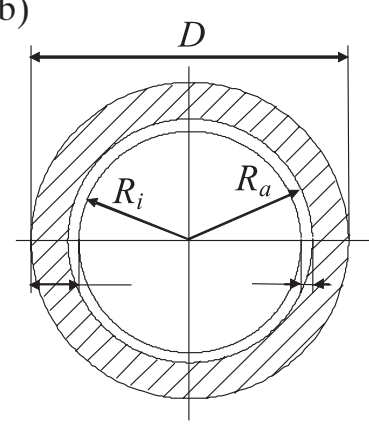

Fig. 3. Hollow cylinder with external (a) and internal (b) transverse annular crack under the action of axial load

In calculating the values of the stress intensity factor $K_{1}$ along the front of external transverse annular cracks (Fig. 3a) let's use the dependence [8]:

$$
K_{I}=\sigma \sqrt{\pi a} \frac{F}{\sqrt{Y}}
$$

where:

$$
\begin{aligned}
& F=\frac{1-R_{i a}^{2}}{\left[1-\left(1-R_{i a}\right) \frac{a}{t}\right]^{2}-R_{i a}^{2}}, \\
& Y=0.8+\left(1-R_{i a}\right) \frac{a}{t} \frac{H}{\left[1-\left(1-R_{i a}\right) \frac{a}{t}\right]},
\end{aligned}
$$




$$
\begin{aligned}
& R_{i a}=\frac{R_{i}}{R_{i}+t}, \\
& H=4+1.08 \frac{R_{i a}}{\left(1-R_{i a}\right)\left(1-\frac{a}{t}\right)} .
\end{aligned}
$$

Critical depth of external transverse annular crack $a_{c}$ was determined from dependence 5 if given $K_{I}=K_{J c}$ considering the desired depth of the well, that is, the weight of the drilling string $(Q)$ :

$$
a_{c}=\frac{K_{J c} Y}{\pi \sigma^{2} F^{2}}
$$

where:

$$
\begin{gathered}
\sigma=\frac{Q}{S_{f}^{*}}, \\
S_{f}^{*}-\text { area of fracture. }
\end{gathered}
$$

In addition, the practical interest of determining the characteristic fatigue crack depth $(a / t)^{*}$ at which the rate of stress intensity factor $K_{I}$ change dramatically increases and, hence, the risk of the defective drill pipe destruction during tripping.

The magnitude of the rate $\left(d K_{I} / d a\right)$ of the stress intensity factor $K_{I}$ change will be determined by using dependence [8]:

$$
\frac{d K}{d a}=0.5 \sigma \sqrt{\frac{\pi}{a}} \frac{F}{\sqrt{Y}}+\sigma \sqrt{\frac{\pi a}{Y}} \frac{d F}{d a}-0.5 \sigma \sqrt{\pi a} \frac{F}{Y^{1.5}} \frac{d Y}{d a}
$$

where:

$$
\begin{aligned}
& \frac{d F}{d a}=\frac{2\left(R_{i a}-1\right)\left[\frac{a\left(R_{i a}-1\right)}{t}+1\right]\left(R_{i a}^{2}-1\right)}{t\left\{\left[1-\left(1-R_{i a}\right) \frac{a}{t}\right]^{2}-R_{i a}^{2}\right\}}, \\
& \frac{d H}{d a}=1.08 \frac{R_{i a}}{t\left(1-R_{i a}\right)\left(1-\frac{a}{t}\right)^{2}},
\end{aligned}
$$




$$
\frac{d Y}{d a}=\frac{\left(1-R_{i a}\right)}{t\left[1-\left(1-R_{i a}\right) \frac{a}{t}\right]}\left\{H+a \frac{d H}{d a}+\frac{H a\left(1-R_{i a}\right)}{t\left[1-\left(1-R_{i a}\right) \frac{a}{t}\right]}\right\}
$$

Let's consider the case of operated drill pipes failure of strength groups " $\mathrm{L}$ " $(D=126.0 \mathrm{~mm}, t=8.0 \mathrm{~mm})$ and "K" $(D=126.0 \mathrm{~mm}, t=8.4 \mathrm{~mm})$.

For these cases, the relevant dimensionless dependence of type 4 is built.

For the considered case (Fig. 4) the relative depth of critical defect is almost identical and amounts $(a / t)^{*}=0.535$.

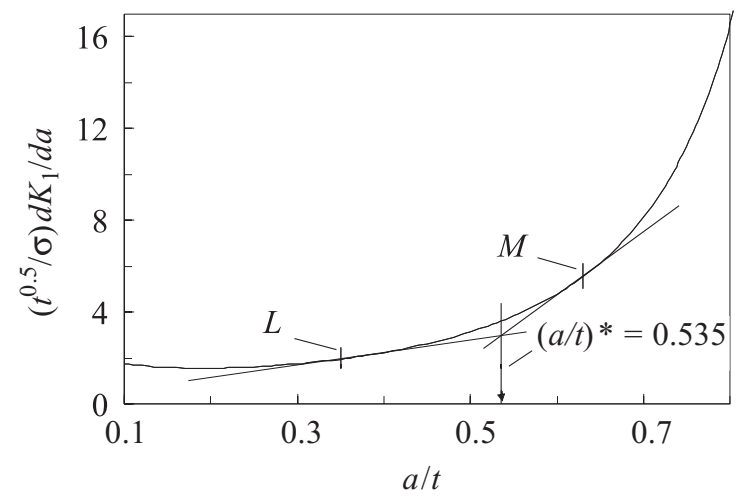

Fig. 4. Evaluation of danger depth of external transverse annular cracks in operated drill pipes of strength groups " $L$ " and " $K$ " under load Q

However, taking into account the destruction of drill pipe metal of strength groups " $L$ " and " $K$ " and using dependence 6, establish the relationship between the critical depth of outer annular transverse fatigue crack $a_{c} / t$ and the weight of the drilling string $Q$.

Represented graphically (Fig. 5) computational results give grounds to conclude that for drill pipes metal of strength "L" during tripping at a depth of $3 \mathrm{~km}$ to $6 \mathrm{~km}$ (0.79 $\mathrm{MN} \leq Q \leq 1.6 \mathrm{MN})$ external transverse annular cracks within the range of $4.3 \mathrm{~mm} \geq a_{c} \geq 2.7 \mathrm{~mm}$ (Fig. 5, part I, curve 1, BD) are critical, whereas at depths of $1 \mathrm{~km}$ to $3 \mathrm{~km}$ fatigue cracks with the depth $a^{*}=4.6 \mathrm{~mm}$ (Fig. 5, part II, DE) are dangerous. For drill pipes metal of strength group " $K$ " during trips at depths of $4 \mathrm{~km}$ to $6 \mathrm{~km}$ (1.05 $\mathrm{MN} \leq Q \leq 1.6 \mathrm{MN})$ the external transverse annular cracks within the range of $4.5 \mathrm{~mm} \geq a_{c} \geq 3.55 \mathrm{~mm}$ (Fig. 5, part I, curve 2, $A C$ ) are critical, while at depths of $1 \mathrm{~km}$ to $4 \mathrm{~km}$ fatigue cracks with the depth $a^{*}=4.5 \mathrm{~mm}$ (Fig. 5, part II, CE) are dangerous. 


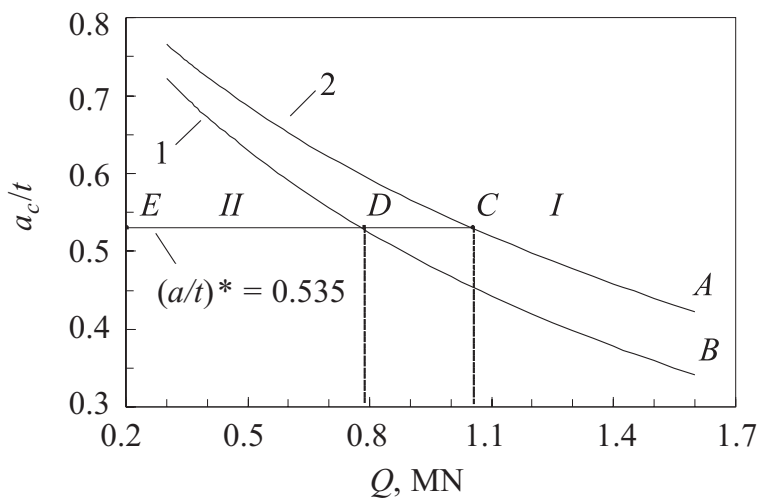

Fig. 5. Relationship between the critical depth of external circumferential transverse cracks in the drill pipe wall of strength groups "L" (1) and "K" (2) and the weight of the drilling string $(\mathrm{Q})$

Let's define the conditions under which the possible destruction of drill pipes of strength groups "L" and "K" containing internal circumferential transverse crack (Fig. $3 b)$ with the depth $(a / t)^{*}$. At the top of this crack [8] the value of stress intensity factor $K_{I}$ is determined by the dependence:

$$
K_{I}=\sigma \frac{F}{\sqrt{1-\frac{a}{t}}} \sqrt{\pi a}
$$

Thus, the rate of change $\left(d K_{I} / d a\right)$ of stress intensity factor $K_{I}$ is equal to:

$$
\frac{d K_{I a}}{d a}=\sigma \frac{d F}{d a} \frac{\sqrt{\pi a}}{\sqrt{1-\frac{a}{t}}}+\frac{\sigma F}{2 t} \frac{\sqrt{\pi a}}{\left(1-\frac{a}{t}\right)^{\frac{3}{2}}}+\frac{1}{2} \frac{\sigma F}{\sqrt{1-\frac{a}{t}}} \sqrt{\frac{\pi}{a}}
$$

where the function $F$ and the rate of its change $d F / d a$ are determined by functional series [8], which depend on the ratio $R_{i} / R_{a}$, where $R_{a}=R_{i}+a$.

Let's set the characteristic depth of internal circumferential transverse crack $(a / t)^{*}$ for investigated elements of operated drill pipes of strength group "L" $(D=126.0 \mathrm{~mm}$, $t=8.0 \mathrm{~mm})$ and "K" $(D=126.0 \mathrm{~mm}, t=8.4 \mathrm{~mm})$. For this purpose dimensionless dependence of type $\frac{\sqrt{t}}{\sigma} \frac{d K_{I}}{d a}=F\left(\frac{a}{t}\right)$ (Fig. 6) is built, and using method [7] defined are the places with a sharp increase in the rate $\left(d K_{I} / d a\right)$ of stress intensity factor $K_{I}$ change during drill pipe trips. The characteristic depth of crack is equal to $(a / t)^{*}=0.705$. 


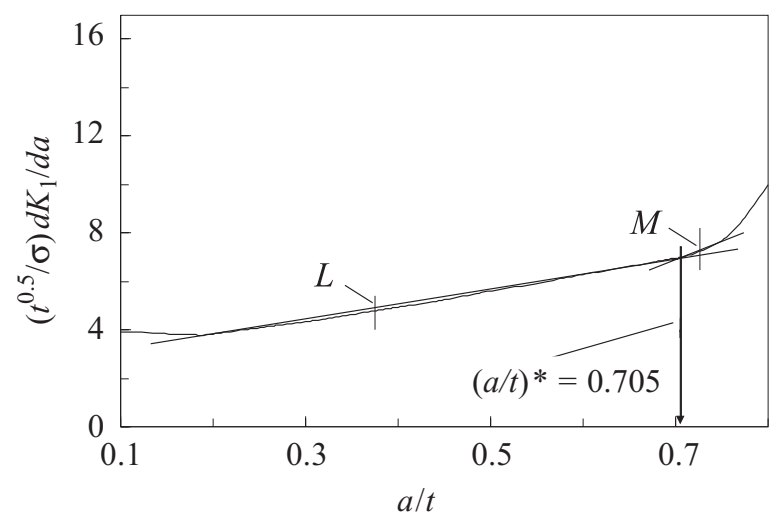

Fig. 6. Evaluation of danger of internal annular transverse crack depth in operated drill pipes of strength groups "L" and "K" under load Q

The typical depth of internal transverse crack equals $a^{*}=5.6 \mathrm{~mm}$ for the drill pipe of strength groups "L" and equals $a^{*}=5.9 \mathrm{~mm}$ for the drill pipe of strength group "K".

The relationship between the critical depth of the internal transverse fatigue crack $a_{c} / t$ for investigated drill pipes and the weight of the drilling string $Q$ was established.

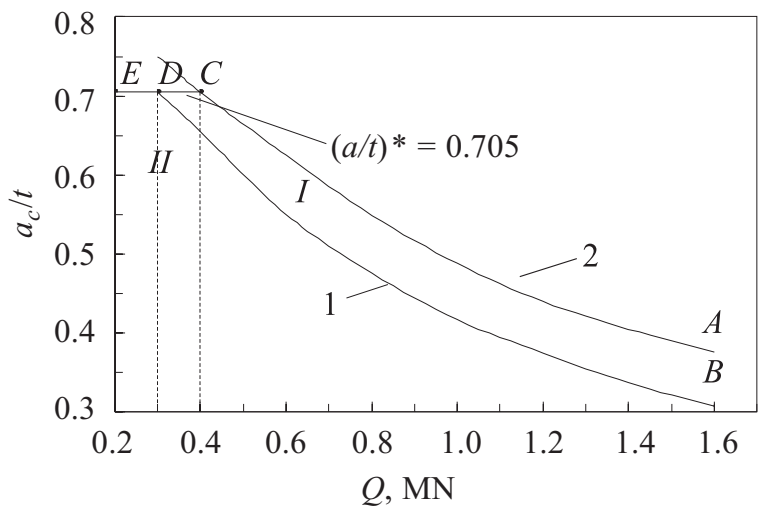

Fig. 7. Relationship between the depth of the critical internal annular transverse crack which is available in the wall of drill pipes of strength groups " $L$ " (1) and "K" (2) and the weight of the drilling string $(\mathrm{Q})$

The results of calculations (Fig. 7) give grounds to conclude that during trips for drill pipes of the strength group "L" at a depth of $1.2 \mathrm{~km}$ to $6 \mathrm{~km}(0.30 \mathrm{MN} \leq Q \leq 1.60 \mathrm{MN})$ critical for drill pipes metal are internal transverse cracks in the ring range $5.6 \mathrm{~mm} \geq a_{c} \geq 2.4 \mathrm{~mm}$ (Fig. 7, section I, curve 1, BD), and for groups of drill pipe strength "K" at the depth of $1.5 \mathrm{~km}$ to $6 \mathrm{~km}(0.46 \mathrm{MN} \leq Q \leq 1.60 \mathrm{MN})$ critical for drill pipes metal are internal circumferential transverse cracks within the range of $5.9 \mathrm{~mm} \geq a_{c} \geq 3.2 \mathrm{~mm}$ (Fig. 7 area 
and curve 2, $C A$ ). While at depths of $1 \mathrm{~km}$ to $1.2 \mathrm{~km}$ for drill pipe of strength group "L" dangerous is the internal circumferential transverse crack with the length $a^{*}=5.6 \mathrm{~mm}$ (Fig. 7, part II, $D E$ ), and for drill pipe of strength groups "K" at depths of $1 \mathrm{~km}$ to $1.5 \mathrm{~km}$ dangerous is internal circumferential transverse cracks with the depth $a^{*}=5.9 \mathrm{~mm}$ (Fig. 7, part II, CE).

The obtained results allow interpreting a substantial increase in the number of accidents of the drill string elements during drill pipe trips described in [1,2].

The analysis of the results of carried out calculations and experimental studies testifies that for evaluation of the failure conditions of longterm operated drill pipes of strength groups "L" and " $\mathrm{K}$ " containing transverse annular cracks it is necessary, at first, to take into account the nature of transverse annular cracks (external or internal) location. Secondly, consider the group strength of drill pipes, thirdly, at shallow depths an indicator "structural element resistance to crack growth" should be considered and at the depths of $1.2 \mathrm{~km}$ to $3 \mathrm{~km}$ - for pipes containing external (areas $A C$ and $B D$ in Fig. 5) or internal ( $A C$ and $B D$ areas in Fig. 7) transverse annular crack - critical stress intensity factor $K_{J c}$ as the characteristic strength criterion of destruction drill pipe metal.

Thus, during tripping the determining factor that leads to a significant increase in the number of accidents of longterm operated drilling strings in deepening wells to depths exceeding $3 \mathrm{~km}$, there is the loss of drill pipe metal resistance to cracks growth. Moreover (see Tab. 4), at these depths more dangerous are internal transverse annular cracks while at depths ranging of $1 \mathrm{~km}$ to $3 \mathrm{~km}$ external transverse annular cracks are more dangerous as the determining factor here is the characteristic depth of fatigue crack $a^{*}$.

Table 4

The value of the depth of critical $a_{c}$ (characteristic $\left.\left(a^{*}\right)\right)$ annular cracks

\begin{tabular}{|c|c|c|c|c|}
\hline \multirow{2}{*}{$\begin{array}{c}H, \\
\mathrm{~km}\end{array}$} & \multicolumn{2}{|c|}{$\begin{array}{c}\text { Critical external annular cross } \\
\text { crack } \\
a_{c}\left(a^{*}\right), \mathrm{mm}\end{array}$} & \multicolumn{2}{c|}{$\begin{array}{c}\text { Critical internal annular cross } \\
\text { crack } \\
a_{c}\left(a^{*}\right), \mathrm{mm}\end{array}$} \\
\cline { 2 - 5 } & strength group "L" & strength group "K" & strength group "L" & strength group "K" \\
\hline 1 & $5.9 ;(4,3)$ & $6.5 ;(4.5)$ & $5.7 ;(5.6)$ & $6.4 ;(5.9)$ \\
\hline 2 & $5.1 ;(4,3)$ & $5.8 ;(4.5)$ & 4.9 & 5.6 \\
\hline 3 & $4.2 ; \sim(4,3)$ & $5.0 ;(4.5)$ & 3.8 & 4.6 \\
\hline 4 & 3.6 & $4.4 ; \sim(4.5)$ & 3.2 & 4.0 \\
\hline 5 & 3.2 & 4.0 & 2.8 & 3.5 \\
\hline 6 & 2.8 & 3.6 & 2.5 & 3.2 \\
\hline
\end{tabular}




\section{CONCLUSIONS}

1. An experimental and calculation procedure for assessing the conditions of critical failure of longterm operated drill pipes containing external or internal circumferential transverse crack during tripping was suggested.

2. Experimental evaluation of the critical stress intensity factor $K_{J C}$ of metal of longterm operated drill pipes for strength groups " $\mathrm{L}$ " and " $\mathrm{K}$ " was done.

3. It was established that destruction of longterm operated drill pipes of strength groups "L" and "K" with external circumferential transverse crack at a depth of more than 3-4 km (depending on the strength group) is determined by the critical crack growth resistance of pipe metal, and in the range of 1 to $3 \mathrm{~km}-4 \mathrm{~km}$ by an indicator "structural element resistance to crack growth." For drill pipes with internal annular transverse crack at a depth of 1.2-1.5 km to $6 \mathrm{~km}$ (depending on strength group) their failure is determined by the crack growth resistance of pipe metal and in the range of $1 \mathrm{~km}$ to $1.2-1.5 \mathrm{~km}$ - by an indicator "structural element resistance to crack growth."

4. The evaluation of conditions of critical failure during tripping of equally loaded drill pipes shows that the internal annular transverse cracks are more dangerous than external ones at depths exceeding $3 \mathrm{~km}$, while in the depth interval from $1 \mathrm{~km}$ to $3 \mathrm{~km}$ the external transverse annular cracks are more dangerous.

5. The obtained results can be applied for technical diagnostics interpretation of longterm operated drill pipes.

\section{REFERENCES}

[1] Artym V.I., Yatsynyak I.I., Grytsiv V.V. et al.: Analysis of corrosion-fatigue failure of the drill string elements. Exploration and Development of Oil and Gas Fields, No. 2 (43), 2012, pp. 197-202.

[2] Pokhmurskii V.I., Kryzhanivskyi E.I., Ivasiv V.M. et al.: The strength and durability of oil and gas equipment. in: Panasiuk V.V. (ed.): Fracture mechanics and strength of materials: reference manual, vol. 10. Lviv-Ivano-Frankivsk, Karpenko Physico-Mechanical Institute of the National Academy of Sciences of Ukraine, Ivano-Frankivsk National Technical University of Oil and Gas, 2006, 1193 p.

[3] Friedman Ya.B.: Mechanical properties of metals. Mechanical testing. Structural strength, vol. 2. 3rd ed. Mashinostroienie, Moscow 1974, 368 p.

[4] Panasiuk V.V.: Mechanics of quasibrittle rupture of materials. Naukova dumka, Kiev 1991, 416 p. 
[5] Grabowskyi R.S., Lepak O.M., et al.: Evaluation of conditions of longterm operated pipelines destruction. Scientific Bulletin of Ivano-Frankivsk National Technical University of Oil and Gas, No. 1 (38), 2015, pp. 46-53.

[6] Calculations and testing on strength. Methods of mechanical testing of metals. Defining characteristics of crack growth resistance (failure viscosity under static load). GOST 25.506-85. Izdatelstvo standartov, Moscow 1985, 62 p.

[7] Dmytrakh I.M., Tot L., Bilyi O.L., Syrotyuk A.M.: Workability of materials and structural elements with chisel shaped stress concentrators. in: V.V. Panasyuk (ed.): Fracture mechanics and strength of materials: reference manual, vol. 13. SPOLOM, Lviv2012, $316 \mathrm{p}$.

[8] Harris D.O.: Stress Intensity Factor for Hollow Circumferentially Notched Round Bars. Trans. ASME: J. of Basic Engineering, 89, 1967, pp. 103-106.

[9] Shuai Luo, Sujun Wu: Effect of stress distribution on the tool joint failure of internal and external upset drill pipes. Materials \& Design, vol. 52, Dec. 2013, pp. 308-314. 